European ophthalmology

\section{European ophthalmology from a British perspective}

\section{Colin M Kirkness}

\section{Series editor: David Taylor}

o this brief overview of ophthalmology, I will inevitably oversimplify and omit some details which others may regard as important. Ophthalmology as a specialty is probably practised in a more diverse fashion throughout the European Union than any other medical subspecialty.

In Britain, ophthalmology is essentially a consultant led practice of ophthalmic surgery. We can work this way because of the presence of approximately 7000 optometrists in the United Kingdom in both hospital and private practice. In many parts of the European Union, however, ophthalmic opticians or optometrists do not exist and opticians are restricted to dispensing spectacles and contact lenses. By the Clausus Medicus or L'Acte Medicale, which restricts examination, diagnosis, and treatment to medically qualified people, European opticians are banned from carrying out many of the practices that are commonplace in the United Kingdom or United States

\section{STRUCTURE OF EUROPEAN OPHTHALMOLOGY}

First, let me make it clear, there are some very fine eye units in other parts of the $\mathrm{EU}$, but the average ophthalmologist in the rest of Europe should not necessarily be equated with the average ophthalmologist in the United Kingdom. In Germany and France, there are each nearly 8000 ophthalmologists but no optometrists. There is nothing remotely equivalent to SWAG (Specialist Workforce Advisory Group) and no central effort is made to control numbers. There are many agreeable small towns in Germany, with populations of no more the 10000 , that can boast at least three ophthalmologists. Clearly, their potential surgical load is small and in practice most would refer patients to the nearest university clinic or occasionally to a cataract centre which may or may not be recognised for training. Even when refraction is taken into account, such practices cannot be overstretched.

Throughout Europe, there is a common pyramidal structure for surgical ophthalmology with professors at the apex of the pyramid. Some such individuals would be prepared to perform most types of surgery and some even provide their own pathology service. One can only admire the skills of such polymaths. The younger generation is probably less likely to adopt this approach and is encouraging a wider subspecialism, but surgery is nevertheless concentrated in the major centres.

Few European countries employ ophthalmologists on a purely salaried basis. In most, ophthalmologists are reimbursed partially or wholly by medical insurance companies either on a privately run or state run basis. In some areas, self referral by patients is possible, bypassing family practitioners.

Standards vary tremendously but, in some areas, patients unable to provide insurance for themselves are poorly catered for.

\section{TRAINING IN OPHTHALMOLOGY IN EUROPE}

The minimum and usual length of training is 4 years but, in several countries, this may be longer. Some, such as the Netherlands, often expect a potential trainee to have spent some time in allied work, such as research towards a $\mathrm{PhD}$ in basic ophthalmic science, before entering the clinical specialty. Other countries have, in effect, two levels of specialisation in ophthalmology; for example, in Germany all trainees complete the initial 4 years in basic training which qualifies the trainee for a state licence with or without an examination. If an individual obtains a faculty position, only then does true surgical training begin. There is no time limit to the training and true independence of practice may only be reached when the individual is given a chair.

Ireland also has two levels of specialisation. Community ophthalmologists may practise after 4 years' experience and once they have obtained FRCSI. Ophthalmic surgeons complete an identical training to those in the UK. The system works extremely effectively and serves Ireland well.

Elsewhere in Europe the systems range from 4 years with a moderate amount of surgical experience in Finland to a very protracted period in Denmark, where doctors are limited to working 36 hours a week including periods on call Often 10 years is needed to obtain sufficient experience, which is very frustrating for junior ophthalmologists. Further south-for example, in Italy, there is no fixed number of trainees and experience may be diluted considerably. In France, trainees rotate between different units that may be widely separated: lack of continuity may be problematic.

In Austria, subspecialism may begin at the start of training and it is possible for a trainee to be exposed to one area only-for example, oculoplastic surgery, and yet satisfactorily complete training.

None of the other EU nations, with the possible exception of Ireland, has such well structured training as that in the UK, with the associated controls of both the local deanery and the Royal College of Ophthalmologists' quinquennial inspections. Moreover, few countries have a rigorous examination system and none as demanding as that in the UK or Ireland. The European Board of Ophthalmology (EBO) tried to rectify this by encouraging bright trainees to take the Diploma of the European Board of Ophthalmology but, so far, it has not achieved wide popularity mainly because there is no significant perceived advantage in obtaining it.

In many ways, the board was addressing the wrong problem. EUPO (an association of European Professors of Ophthalmology) recognised that there were greatly varying standards of teaching throughout Europe. In an effort to begin to address this lack, an annual week long teaching course was established which proved to be hugely popular, attracting as many as 500 or more trainees. However, five days of intensive lectures is no substitute for a year's practical teaching. The EBO encouraged units to achieve minimal standards of good practice broadly in keeping with the Royal College of Ophthalmologists' guidelines for BST (basic specialist training), but as yet only a handful of the approximately 500 departments in the EU have asked to be inspected. European ophthalmology unfortunately lacks any cohesive body that could encourage the development of standards.

In spite of the disparity in training between the UK and Europe, trainees who complete training under their own national regulations and, by virtue of the fact that they are on their own specialist register, are eligible for entry to the British register. It is important that this is recognised and understood by those drawing up job descriptions and by appointment committees if they wish to avoid costly lawsuits by disgruntled European candidates.

\section{CONCLUSION}

Europe does not lack talent but it does lack a cohesive structure for ophthalmol- 
ogy that results in a lack of major research funding and a differential delivery of health care throughout the EU. Some of these problems are insoluble inour loose political alliance but many could at least be improved at a supranational level by greater cooperation and willingness to accept new standards.

Br J Ophthalmol 2002;86:128-129
Author's affiliation

C M Kirkness, Tennent Institute of

Ophthalmology, University of Glasgow, Upper

Ground Floor, Gartnavel General Hospital,

Glasgow G12 OYN, UK

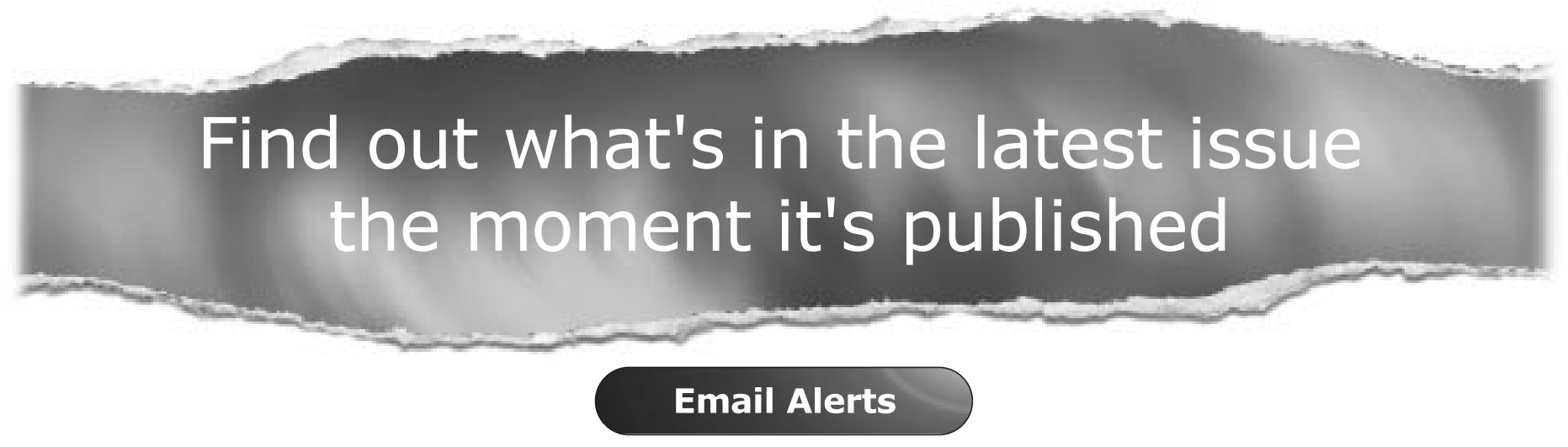

Sign up to receive the table of contents by email every month. You can select from three alerts: Table of Contents (full), TOC Awareness (notice only); British Journal of Ophthalmology related announcements.

\section{www.bjophthalmol.com}

